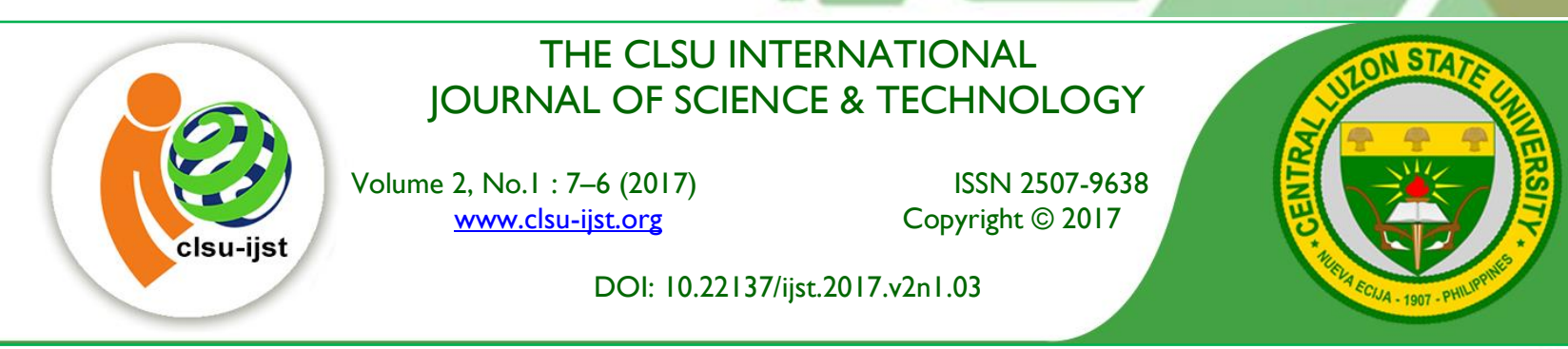

\title{
Mycelial Growth, Fruiting Body Production and Proximate Composition of Pleurotus djamor on Different Substrate
}

\author{
Leilidyn Y. Zurbano ${ }^{1}$, Arce D. Bellere ${ }^{2}$, and Ludivina C. Savilla ${ }^{3}$ \\ ${ }^{1}$ Polytechnic University of the Philippines, ${ }^{2}$ Central Bicol State University of Agriculture, \\ Philippines, ${ }^{3}$ Central Bicol State University of Agriculture,Philippines \\ Email for correspondence: leydenzurbano@gmail.com \\ Submitted 21 March 2017, Accepted 30 April 2017, Published online 31 March 2017
}

\begin{abstract}
Pleurotus djamor is a exotic wood-rotting edible mushroom in the Philippines. The mycelial growth and fruiting body performance of $P$. djamor were evaluated in different culture media, spawning materials, and substrate formulations. The proximate composition of this mushroom was also analyzed. Coconut water gelatin (CWG) showed the fastest mycelial growth which completely colonized the media in 8.2 days of incubation. Sweet sorghum grain was the best spawning material. Moreover, a combination of rice straw, cocopeat, and rice bran at 7:3:1 ratio recorded the most number of flushes (6.6), highest yield $(256.6 \mathrm{~g})$, and highest biological efficiency $(31.10 \%)$. This substrate formulation had the highest NPK content. In proximate composition analysis, $P$. djamor grown in rice straw and cocopeat combination contained $90.15 \pm 0.27 \%$ moisture, $0.87 \pm 0.22 \%$ ash, $0.12 \pm 0.00 \%$ crude protein, $0.17 \pm .01 \%$ crude fat, $3.10 \pm 0.24 \%$ crude fiber, and $5.59 \%$ nitrogen free extract or digestible carbohydrate content.
\end{abstract}

Keywords: Pleurotus djamor, proximate composition, total N, P and $K$ of the fruiting substrates, mycelial run

\section{INTRODUCTION}

In the Philippines, mushroom production is still limited it is dominated by small-scale mushroom growers which produce about 200 tons of oyster mushroom per year. The volume of mushroom production has been decreasing from 1992 - 2009 because of the intensification of rice production. However, the possibility to increase mushroom production is very feasible since there is an increase in demand due to growing awareness about the health benefits of mushroom (Chang et al., 2014). Mushrooms are still being imported from other countries which indicate that there is no steady supply of mushroom in the Philippine market.

Pink oyster mushroom, scientifically known as Pleurotus djamor, is an edible species of fungi that has a vibrant pink color and ruffled appearance. Other common names include flamingo oyster, 
salmon oyster, and strawberry oyster (Stamets , 2000). Native to the tropics, the pink oyster fruits are abundantly found in warmer temperatures. It is extremely productive during mid-summer when other varieties are stunted by extreme heat. Nutritionally, it contains high levels of protein (about 30\% of dry weight) and essential elements such as vitamins, minerals, and polysaccharides (Chang and Miles , 2004).

P. djamor has the ability to grow on untreated, raw cellulosic waste such as rice straw, coconut peat and husk, sawdust, banana leaf litters, and grasses. Its rate of colonization, short but productive fruiting cycle, and adaptability to diverse substrate materials make this species affordable to many cultivators, especially those in developing countries. However, problems on the utilization of raw materials arise due to lack of knowledge on suitable substrates for $P$. djamor production. Therefore, this study evaluated the mycelial growth and fruiting body production of $P$. djamor using indigenous locally available cellulosic substrates in order to establish production technology for this mushroom. The proximate composition of this mushroom grown on the different formulated substrate was also highlighted in this study.

\section{MATERIALS AND METHODS}

\section{Source of Mushroom}

The fruiting bodies of P.djamor were obtained from the Tissue Culture Laboratory of Polytechnic University of the Philippines in Lopez, Quezon. These were tissue cultured in potato sucrose gelatin plates and incubated for 5 days to allow mycelial growth. The plate cultures served as inoculant in the evaluation of the media.

\section{Evaluation of Mycelial Growth in Different Culture Media}

The nutritional requirements of $P$. djamor were evaluated using four indigenous culture media, namely: rice bran D1 decoction gulaman, local yellow corn grit decoction gulaman, sweet potato decoction gulaman, mature coconut water gulaman, and potato sucrose gulaman. Fifty grams of each rice bran, corn grit, and sweet sorghum was prepared and boiled separately in one liter of water until viscosity was attained. On the other hand, 250 grams of potato cubes was boiled in one liter of water until tender. After boiling, the cubes of potato were separated from the decoction. Decoctions were strained and reconstituted to complete the one-liter volume by adding distilled water.

Twenty grams of white gulaman and 10 grams of sucrose were added into the decoction and boiled again with constant stirring until homogenous. One liter of fresh coconut water was filtered using cheesecloth, then 20 grams of white gulaman was added and boiled with continuous stirring until a homogenous mixture was attained. The newly prepared media were sterilized at $15 \mathrm{psi}, 121^{\circ} \mathrm{C}$ for 20 minutes and dispensed into sterile plates.

To assure uniformity in the age of the inoculum, a seven-day old pure culture of secondary mycelia was used for evaluation of growth in the different culture media. Using a sterile cork borer, 10 mm-diameter mycelial discs were prepared and inoculated centrally on the prepared medium. The inoculated plates were sealed with parafilm and incubated at $32{ }^{\circ} \mathrm{C}$ under alternating light and dark conditions. The diameter of mycelial growth was measured using a vernier caliper every 24 hours until the full ramification of each medium. Each set-up was replicated three times. 


\section{Evaluation of Grain Spawning Materials}

To evaluate the mycelial growth performance of $P$. djamor in the different spawning materials, unmilled rice, corn grit, and sorghum seeds were used. These materials were boiled until tender. These were drained, and 100 grams of each were dispensed into clean catsup bottles. The bottled substrates were plugged with cotton, wrapped with clean paper and sterilized at 15 psi, $121{ }^{\circ} \mathrm{C}$ for 45 minutes. After sterilization and cooling, the bottled substrates were inoculated with $10 \mathrm{~mm}$ fungal disc from 7day old pure culture and incubated at room temperature $\left(32^{\circ} \mathrm{C}\right)$ to allow ramification of the mycelia. The number of days of full mycelial colonization in the different mother spawning materials was recorded. The substrate which had the full ramification of the mycelia in the shortest period of time was the criterion in choosing the best spawning material.

\section{Fruiting Body Performance of $P$. djamor on the Different Substrate Formulations}

Rice straw, dried banana leaves, and coconut husks were soaked overnight in separate drums; subsequently they were rinsed with clean water. They were manually chopped into approximately 1 inch length. Five substrate formulations were prepared in 7:3:1 w/w: (T1) rice straw (RS): good lumber sawdust (GLS) : rice bran (RB); (T2) rice straw (RS): coconut peat (CP): rice bran (RB); (T3) rice straw (RS): coconut lumber sawdust (CLS): rice bran (RB); (T4) rice straw (RS): coconut husk $(\mathrm{CH})$ : rice bran (RB); and (T5) rice straw (RS): dried banana leaves (DBL): rice bran (RB) with 65-70\% moisture content. Samples of the different substrate formulations were brought to Regional Soils Laboratory, Lipa City, Batangas, Philippines for the determination of $\mathrm{pH}$, moisture content, N, P, and K content

Five hundred grams of formulated substrates were bagged and compacted in a $6 \times 12$-inch polypropylene bag. The bags were plugged with cotton and pasteurized at $80{ }^{\circ} \mathrm{C}$ for 6 hours. The sterilized bags were allowed to cool before inoculation with 10 grams of best grain spawn of $P$. djamor from the previous study. The inoculated bags were incubated in the mushroom house at $32{ }^{\circ} \mathrm{C}$ to allow full ramification of mycelia on the formulated substrates. Bags with fruiting initials (primordia) were opened to allow maturation of basidiocarp. Matured fruiting bodies were harvested and weighed to determine biological efficiency. The number of flush of fruiting body was also noted.

\section{Proximate Composition Analysis}

The fruiting bodies grown on the best substrate formulation were subjected to proximate analysis. The moisture, proteins, crude fibers, fats, and NFE content of mushroom were analyzed.

\section{Statistical Analysis}

Data were analyzed using one-way analysis of variance (ANOVA) and the treatment means were compared using Scheffe's Multiple Comparison Post Hoc Test at $\mathrm{P}<0.05$ significance.

\section{RESULTS AND DISCUSSION}

\section{Mycelial Growth of P. djamor on Different Culture Media}

Mycelia are the vegetative part of a fungus consisting of a mass of branching, thread-like hyphae. The luxuriant growth of mycelia depends on the nutritional content of the medium where they grow. In this study, the mycelia growth response of $P$. djamor on different indigenous media was evaluated. The daily mycelial growth diameter of $P$. djamor is shown in Figure 1 . It can be seen that during the first four days, Sweet Potato Sucrose Gulaman (SPSG) recorded the widest mycelial 
diameter, followed by Corn Grit Sucrose Gulaman (CGSG), Rice Bran Sucrose Gulaman (RBSG), and Potato Sucrose Gulaman (PSG). During this period, Coconut Water Gulaman (CWG) had the lowest diameter. However, on the sixth day, mycelial growth in CWG showed the fastest mycelial run. The culture plates of $P$. djamor on the different media are shown in Figure 2. The ability of coconut water to stimulate rapid mycelial growth of $P$. djamor is attributed to its nutritional content. It has a unique chemical composition of sugars, vitamins, minerals, amino acids and phytohormones (Prades et al. 2012; Yong et al. 2009). Thus, the presence of all those could give faster mycelial run, and thicker and denser mycelia.

In the Philippines, coconut is always abundant and mature coconut water is a waste product compared to young coconut water. Many researches have steered the use of coconut water as an effective media that supports mycelial growth of different mushroom species (Radenahmad et al., 2009). As Santoso et al. (1999) reported, mature coconut water contains 92\% sucrose making it suitable for the cultivation of mycelia. Moreover, the protein content of coconut water increases as it matures from $0.13 \%$ to $0.29 \%$. This level was enough to fulfill the nitrogen requirement of the growing mycelia (Rau , 1999). The result of the study is in congruence with the study of Magday et al. (2014) who reported that $\mathrm{CWG}$ of $\mathrm{pH} 6.0$, and in sealed and lighted conditions at room temperature $\left(32{ }^{\circ} \mathrm{C}\right)$ yielded the most efficient mycelial growth. Furthermore, it was also stated by Jacob et al. (2015) that CWG supported the luxuriant mycelial growth of Pleurotus citrinopileatus, Pleurotus djamor, and Pleurotus salmoneostramineus.

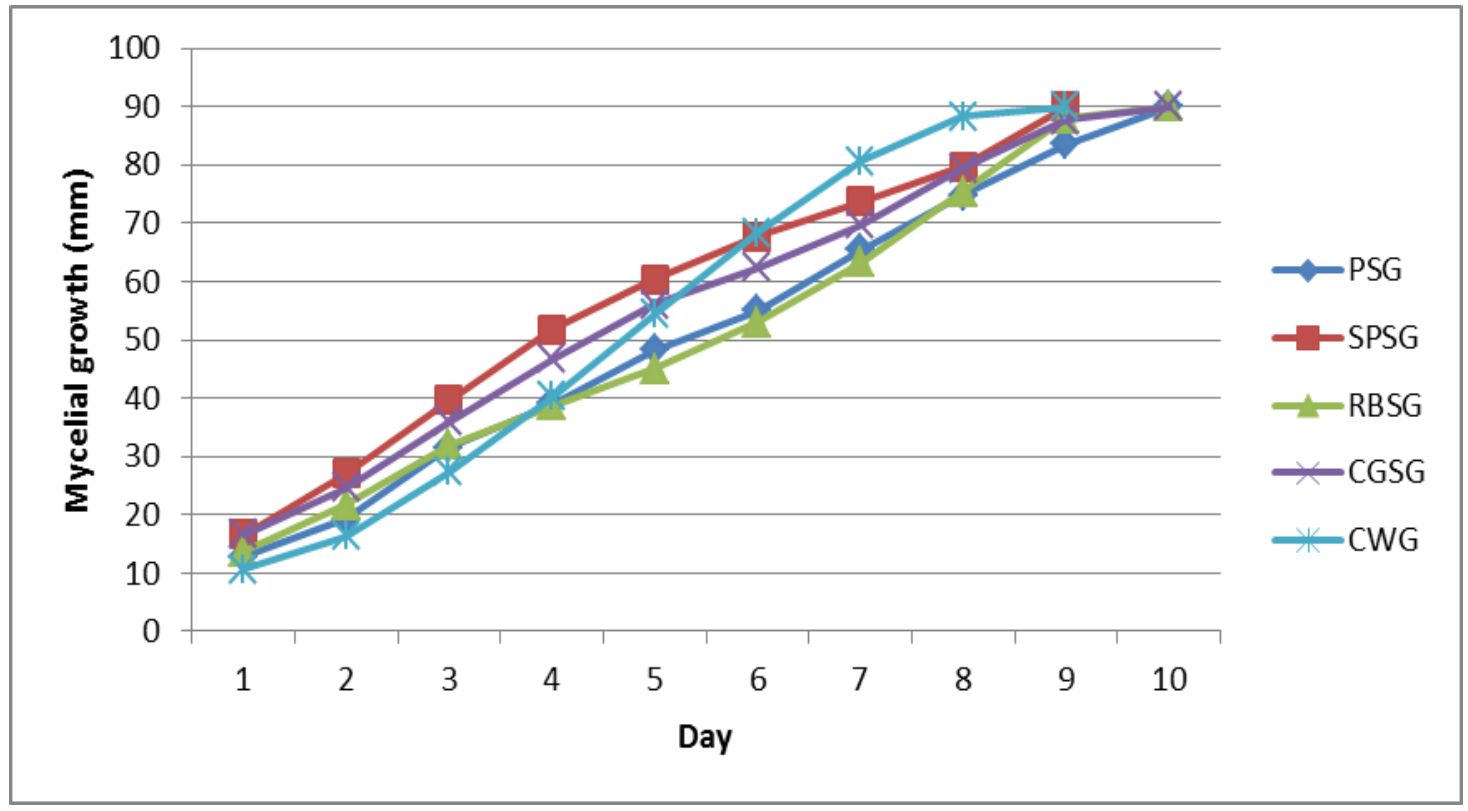

Figure 1. Daily mycelial growth diameter $(\mathrm{mm})$ of P. djamor on different indigenous media.

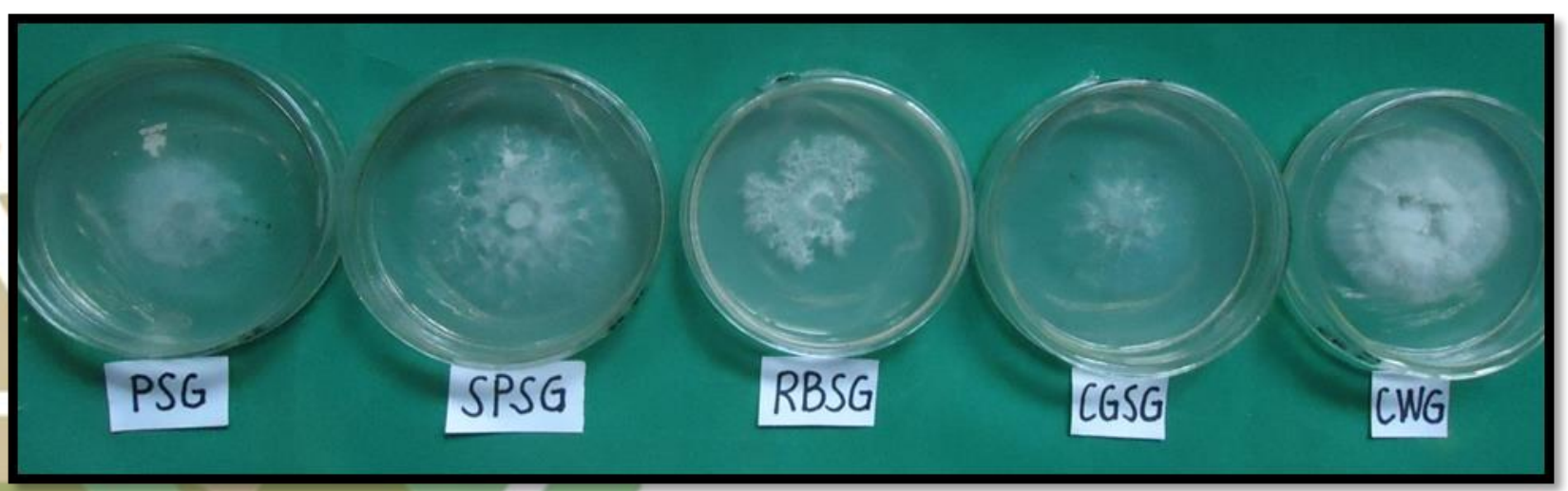

\begin{tabular}{l|l|l|l|} 
Vol. 2 No. 1 (March 2017) & ISSN: 2507-9638| DOI: $10.22137 /$ ijst.2017.v2n1.03 \\
\hline
\end{tabular} 
Figure 2. Culture plate of $P$. djamor on different indigenous media 5 days after inoculation.

In terms of incubation period (Table 1), P. djamor inoculated in PSG (pH 6.4) had the slowest mycelial run at 10.0 days. It is significantly different to RBSG (pH 6.2) and CGSG (pH pH 6.1) which were ramified 9.2 days after inoculation, SPSG ( $\mathrm{pH}$ 6.4) which was fully colonized on the $9^{\text {th }}$ day after inoculation, and CWG ( $\mathrm{pH}$ 3.6) which was ramified at 8.2 days of incubation. Nonetheless, the number of days of full colonization of $P$. djamor grown in RBSG, CGSG, and SPSG were not significantly different from each other. CWG, on the other hand, had the fastest mycelial ramification and significantly different from the other treatments.

Table 1. Number of days of incubation of $P$. djamor on different indigenous media.

\begin{tabular}{lc}
\hline \multicolumn{1}{c}{ Culture Media } & Incubation Period (day) \\
\hline Potato Sucrose Gulaman (PSG) & $10.0^{\mathrm{a}}$ \\
Sweet Potato Sucrose Gulaman (SPSG) & $9.0^{\mathrm{b}}$ \\
Rice Bran Sucrose Gulaman (RBSG) & $9.2^{\mathrm{b}}$ \\
Corn Grit Sucrose Gulaman (CGSG) & $9.2^{\mathrm{b}}$ \\
Coconut Water Gulaman (CWG) & $8.2^{\mathrm{c}}$ \\
\hline
\end{tabular}

Note: In a column, the same letters of superscript indicate insignificantly difference by Scheffe's Multiple Comparison Post Hoc Test $(\mathrm{P}>0.05)$.

\section{Mycelial Growth of $P$. djamor on Different Spawning Materials}

Mushroom spawn is the mushroom mycelium growing on a given substrate. It serves as the planting material in mushroom cultivation. Spawn quality is the most important factor in the production of edible mushroom (Awi-Waadu and Stanley , 2010). Furthermore, Chang and Miles (1997) noted that mushroom spawning is a process of cellular expansion in order to produce more mycelia for mass production. In this study, the mycelial response of $P$. djamor on different spawning materials was evaluated and the data are shown in Table 2. Sweet sorghum had the shortest day of incubation period with a mean of 9.6 days, followed by rice grains with 13.2 days (Figure 3). Faster mycelial growth on sorghum could be attributed to their high carbohydrate, fats, and protein components. Furthermore, larger surface area and pores between grains support faster mycelium growth rate (Tinoco et al., 2001). This would mean increased aeration resulting in improved respiration by the mycelia, hence, significantly higher growth rate (Nahr et al., 2011).

Table 2. Number of days of incubation of $P$. djamor on different spawning materials.

\begin{tabular}{lc}
\hline \multicolumn{1}{c}{ Culture Media } & Incubation Period (day) \\
\hline Sweet Sorghum & $9.6^{\mathrm{c}}$ \\
Rice Grains & $13.2^{\mathrm{b}}$ \\
Corn Grits & $17.6^{\mathrm{a}}$ \\
\hline
\end{tabular}

Note: In a column, the same letters of superscript indicate insignificantly difference by Scheffe's Multiple Comparison Post Hoc Test $(\mathrm{P}>0.05)$. 


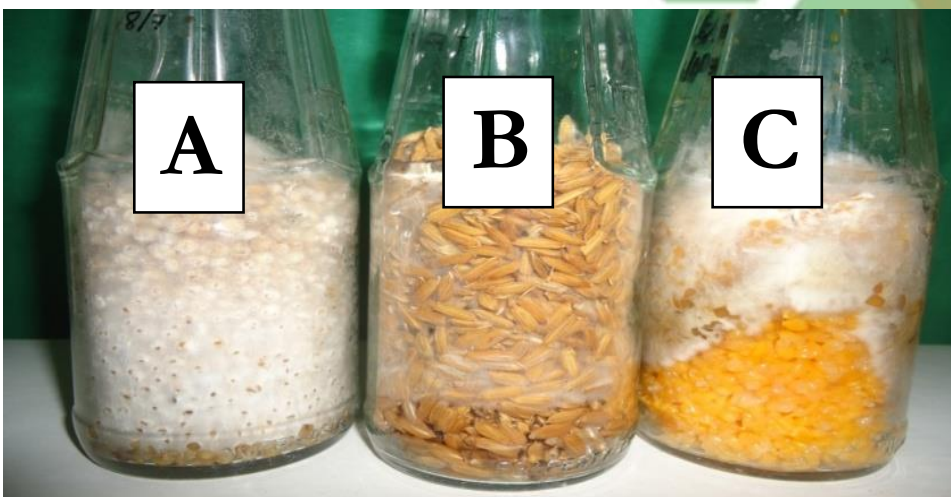

Figure 3. Mycelial growth of $P$. djamor on different spawning materials, namely (A) sweet sorghum, (B) rice grain, and $(\mathrm{C})$ corn grits after 10 days after incubation.

\section{Chemical Content of Formulated Substrates}

An important factor for good production of oyster mushroom is $\mathrm{pH}$. Most of the mushrooms grow and perform well at $\mathrm{pH}$ near to neutral or slightly basic (Khan et al., 2013). Furthermore, $\mathrm{pH}$ has an effect on the metabolic processes, and thus, upon the ability of the mushrooms to use certain substances for their nutritional needs (Miles and Chang , 1997). Most fungi require high moisture levels for the optimum mycelial growth. One of the most important considerations is the moisture content of the substrates which should range from $50-75$ percent. Nitrogen must be provided for the synthesis of all nitrogen-containing compounds such as proteins, purines, pyrimidines, and for the cell wall components, chitin. Phosphorus is present in ATP, nucleic acid, and phospholipids of membranes. Thus, it is a constituent member of compounds functioning in energetic, heredity, protein synthesis, and in the movement of materials across membranes. Potassium, on the other hand, is the most abundant metallic element among fungi. It is a cofactor in some enzyme systems. Loss of potassium could be detrimental for fungus (Miles and Chang, 1997).

Table 3 presented the chemical constituents of the five formulated substrates. The $\mathrm{pH}$ of various substrates ranged from 7.50 to 7.90 with RS: BLL: RB as the highest and RS: CP: RB as the lowest. Moisture content, on the other hand, ranged from 63.90 to 74.60 in which RS: $\mathrm{CH}$ : RB had the highest amount of moisture while RS: CLS: RB had the lowest. In terms of N, RS: CH: RB had the highest content (1.351\%), followed by RS: CP: RB (1.241\%), RS: CLS: RB followed $(0.725 \%)$ and then RS: BLL: RB and RS: GLS: RB (0.350\% and $0.141 \%)$, respectively. On the other hand, RS: CP: RB got the highest $\mathrm{P}_{2} \mathrm{O}_{5}(0.316 \%)$, followed by RS: CLS: RB (0.225\%), RS: CH: RB (0.168), RS: BLL: RB $(0.142 \%)$ and RS: GLS: RB with $0.100 \%$. In terms of $\mathrm{K}_{2} \mathrm{O}$ content, RS: CP: RB had the highest $(0.311 \%)$ followed by RS: BLL: RB with (0.307\%), RS: CLS: RB (0.295\%), RS: CH: RB (0.286\%), and RS: GLS: RB (0.278\%). As for the total NPK, RS: CP: RB had the highest (1.841\%), followed by RS: $\mathrm{CH}: \mathrm{RB}(1.805 \%)$, and RS: CLS: RB (1.245). Conversely, RS: BLL: RB and RS: GLS: RB had a total NPK of $0.799 \%$ and $0.519 \%$

Rice bran supplements the organic nitrogen which helps in the production of higher yields (Arisha , 2010). Cereal straw used for cultivation of oyster mushroom is a poor source of nitrogen $(0.8 \%)$ and at the time of fructification when most of the nitrogen is utilized for mycelial growth, the depleted nitrogen in the substrate becomes inadequate and limits mushroom yield (Victor and Ifeanyi, 2013). Based on the results of the study, RS: CP: RB and RS: CH: RB had a nitrogen content higher than the nitrogen content of most of the substrates employed for mushroom cultivation which usually ranged from $0.5-0.8 \%$ (Gupta and Vijay , 1991). 
Table 3. pH, Moisture, N, P, and K content of the five formulated substrates

\begin{tabular}{|c|c|c|c|c|c|c|}
\hline Treatment & $\mathrm{pH}$ & $\begin{array}{c}\text { Moisture } \\
\text { Content } \\
(\%)\end{array}$ & $\begin{array}{l}\text { Total } \\
\text { N }(\%)\end{array}$ & $\begin{array}{c}\text { Total } \\
\mathbf{P}_{2} \mathbf{O}_{5}(\%)\end{array}$ & $\begin{array}{c}\text { Total } \\
\mathrm{K}_{2} \mathrm{O} \\
(\%)\end{array}$ & $\begin{array}{l}\text { Total } \\
\text { NPK }\end{array}$ \\
\hline $\begin{array}{l}\text { T1 - (RS:G:S:RB) Rice straw }+ \\
\text { good lumber sawdust + rice bran }\end{array}$ & 7.85 & 70.40 & 0.141 & 0.100 & 0.278 & 0.519 \\
\hline $\begin{array}{l}\mathrm{T} 2 \text { - }(\mathrm{RS}: \mathrm{CP}: \mathrm{RB}) \text { Rice straw }+ \\
\text { cocopeat + rice bran }\end{array}$ & 7.50 & 71.10 & 1.214 & 0.316 & 0.311 & 1.841 \\
\hline $\begin{array}{l}\text { T3 - (RS:CLS:RB) Rice straw + } \\
\text { coco lumber sawdust }+ \text { rice bran }\end{array}$ & 7.65 & 63.90 & 0.725 & 0.225 & 0.295 & 1.245 \\
\hline $\begin{array}{l}\mathrm{T} 4 \text { - (RS:CH:RB) Rice straw + } \\
\text { cocohusk + rice bran }\end{array}$ & 7.79 & 74.60 & 1.351 & 0.168 & 0.286 & 1.805 \\
\hline $\begin{array}{l}\text { T5 - (RS:BLL:RB) Rice straw + } \\
\text { banana leaf litters }+ \text { rice bran }\end{array}$ & 7.90 & 69.90 & 0.350 & 0.142 & 0.307 & 0.799 \\
\hline
\end{tabular}

\section{Fruiting Body Performance of $P$. djamor on Different Substrate Formulations}

The fruiting body production of $P$. djamor on the different substrates was also investigated in the present study. The results are presented in Table 4. It can be seen that RS: CP: RB had the highest yield and BE (256.6 g and 31.10\%), followed by RS: CLS: RB (202.4 g and 24.53\%), which were not significantly different from each other. It was followed by RS: CH: RB (167.4 g and 20.29\%), and RS: BLL: RB (158.2 $\mathrm{g}$ and 19.18\%). On the other hand, the control treatment (RS: GLS: RB) registered the lowest yield and BE (113.4 g and 13.75\%) which was significantly different from RS: CP: RB and RS: CLS: RB but not significantly different to RS: $\mathrm{CH}$ : RB and RS: BLL: RB. In terms of flush, RS: CP: RB (6.6) and RS: CLS: RB (6.4) had more number of flushes which were not significantly different from RS: GLS: RB (5.4) and RS: BLL: RB (5.4) but significantly different ( $p<0.05)$ from RS: CH: RB (3.6). On the other hand, RS: GLS: RB and RS: BLL: RB were not significantly different from RS: $\mathrm{CH}: \mathrm{RB}$.

Higher yield, N, P, and $\mathrm{K}$ contents were noted in RS: CP: RB combination. This clearly indicates that NPK content of the substrate influence the yield and biological efficiency of $P$. djamor. This finding is congruent with the study of Moyin-jesu et al. (2012) who reported that there was a gradual increase in average and total yield of mushroom as the nutrient concentration increases. However, they also stated that increasing it further could increase chances for other fungi to compete with the mushroom spore for available nutrient thereby could create a suitable environment for contamination. Furthermore, Custodio (2004) found that cellulose and lignin contents are important components of any substrate since the lignocellulytic enzymes of oyster mushrooms convert them into carbohydrates which serve as the energy source. Cellulose-rich substrates give better yield and helps in enzyme production, which is correlated with higher yield (Arisha , 2010). Coconut peat contains $53.5 \%$ lignin and $35.99 \%$ cellulose (Israel et al. 2011) which was relatively higher than the lignin and cellulose of good lumber sawdust (35-45\% and $20-25 \%$ ) (Sjostrom , 1993); coconut husk (45-55\% and $25-50 \%$ ) (Ding et al., 2012); and banana leaves (13.3\% and 37.3\%) (Mohapatra , 2010). Although, coconut lumber sawdust have higher cellulose content $(54.78 \%)$ than coconut peat, it has lower lignin content $(28.47 \%$ ) than the latter. Likewise, rice straw contains $32 \%$ cellulose and $22.3 \%$ lignin (Xiao et al., 2001). Their lignin and cellulose components were much higher than the other substrates combined with rice straw, hence, the reason for the higher yield obtained. 
Table 4. Number of flushes, yield and biological efficiency (BE) of $P$. djamor on different formulated substrates.

\begin{tabular}{lccc}
\hline \multicolumn{1}{c}{ Substrates } & No. of flush & Yield (g) & BE (\%) \\
\hline $\begin{array}{l}\text { T1 (Control) - 7:3:1 - rice straw (RS): good } \\
\text { lumber sawdust (GLS): rice bran (RB) }\end{array}$ & $5.4^{\mathrm{ab}}$ & $113.4^{\mathrm{c}}$ & $13.7^{\mathrm{c}}$ \\
$\begin{array}{l}\text { T2 - 7:3:1 - rice straw (RS): coconut peat (CP): } \\
\text { rice bran (RB) }\end{array}$ & $6.6^{\mathrm{a}}$ & $256.6^{\mathrm{a}}$ & $31.1^{\mathrm{a}}$ \\
$\begin{array}{l}\text { T3 - 7:3:1 - rice straw (RS): coconut lumber } \\
\text { sawdust (CLS): rice bran (RB) }\end{array}$ & $6.4^{\mathrm{a}}$ & $202.4^{\mathrm{ab}}$ & $24.5^{\mathrm{ab}}$ \\
$\begin{array}{l}\text { T4 - 7:3:1 - rice straw (RS): coconut husk } \\
\text { (CH): rice bran (RB) }\end{array}$ & $3.6^{\mathrm{b}}$ & $167.4^{\mathrm{bc}}$ & $20.3^{\mathrm{bc}}$ \\
$\begin{array}{l}\text { T5 - 7:3:1 - rice straw (RS): banana leaf litters } \\
\text { (BLL): rice bran (RB) }\end{array}$ & $5.4^{\mathrm{ab}}$ & $158.2^{\mathrm{bc}}$ & $19.2^{\mathrm{bc}}$ \\
\hline
\end{tabular}

Note: In a column, the same letters of superscript indicate insignificantly difference by Scheffe's Multiple Comparison Post Hoc Test ( $\mathrm{P}>0.05)$.

The quality of fruiting bodies of $P$. djamor from each substrate formulations was noted. $P$. djamor obtained from RS: GLS: RB, RS: CLS: RB, RS: CH: RB, and RS: BLL: RB had a beige color as they matured and resembled $P$. florida though the edges were curling. However, mushrooms harvested on RS: CP: RB exhibited a radiant pink color even at maturity, and thicker than those from other treatments (Figure 4).

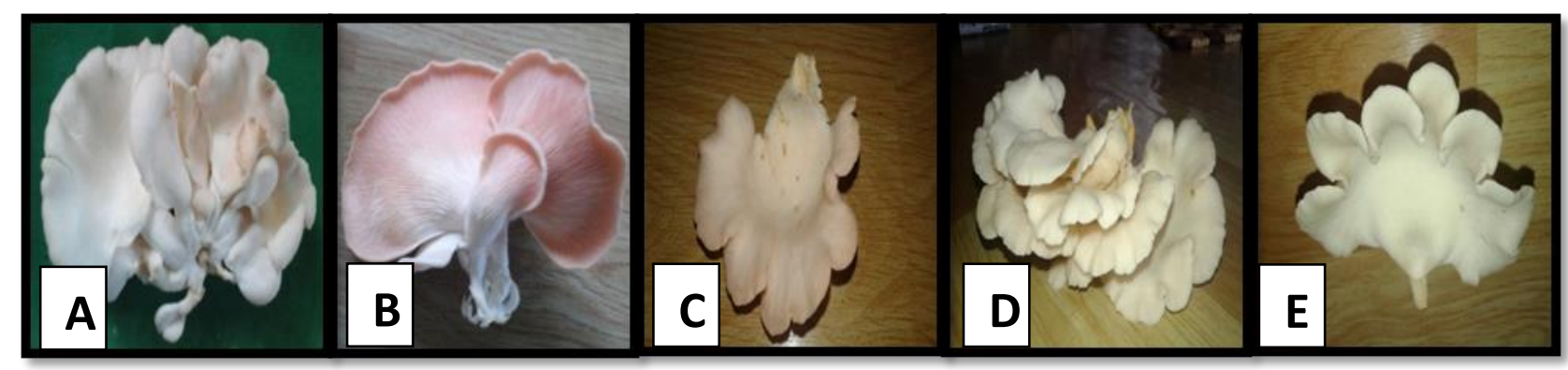

Figure 4. P. djamor fruits harvested on different fruiting substrates, namely (A) rice straw + good lumber sawdust + rice bran; $(\mathrm{B})$ rice straw + cocopeat + rice bran; $(\mathrm{C})$ rice straw + coco lumber sawdust + rice bran; (D) rice straw + coco husk + rice bran; and $(\mathrm{E})$ rice straw + dried banana leaf litters + rice bran.

\section{Proximate Composition of $P$. djamor}

In order to establish the nutrient composition of the fruiting bodies grown on the best formulation, proximate analysis was carried out. The results of the analysis are presented in Table 5 . Fruiting bodies of $P$. djamor grown on best substrate contained $90.15 \pm 0.27 \%$ moisture, $0.87 \pm 0.22 \%$ ash, $0.12 \pm 0.00 \%$ crude protein, $0.17 \pm .01 \%$ crude fat, $3.10 \pm 0.24 \%$ crude fiber, and $5.59 \%$ nitrogen free extract (NFE) or digestible carbohydrate content. 
Table 5. Proximate composition of $P$. djamor grown in rice straw, coco peat, and rice bran combination.

\begin{tabular}{lc}
\hline \multicolumn{1}{c}{ Nutrient Composition } & Amount (\%) \\
\hline Moisture & $90.15 \pm 0.27$ \\
Ash & $0.87 \pm 0.22$ \\
Crude Protein & $0.12 \pm 0.00$ \\
Crude Fat & $0.17 \pm 0.01$ \\
Crude Fiber & $3.10 \pm 0.24$ \\
Nitrogen Free Extract (NFE) & 5.59 \\
\hline
\end{tabular}

Although coco peat and rice straw are high in lignin and cellulose, they have low levels of nutrients. The lower percentage of nutrients such as protein, fats, NFE, and fiber present in the fruiting bodies could be attributed to the low nutrient content of substrates. Combination of rice straw and coco peat supplemented with rice bran had $1.214 \%$ of $\mathrm{N} \%, 0.316 \% \mathrm{P}$, and $0.311 \%$ of $\mathrm{K}$ with a $\mathrm{pH}$ of 7.5 and moisture of 71.10 .

The nutritional composition of mushrooms is affected by many factors. These include strain differences, composition of the substrate, and the environmental factors. The genetic nature of a strain coupled with its metabolism determine how it utilizes nutrients to the substrates and effect of the substrate on the composition of the mushroom (Chang and Hayes , 1978). They also reported that the intrinsic compositional variability in the mushroom was a major factor contributing to the differences in the nutritional composition of strains.

\section{CONCLUSIONS}

P. djamor recorded the fastest mycelial growth in coconut water gulaman. Sweet sorghum had the fastest mycelial ramification as spawning granulated material. Combination of rice straw, coco peat and rice bran in a 7:3:1 ratio had the highest total $\mathrm{N}, \mathrm{P}$, and $\mathrm{K}$ and had the most number of flushes, highest yield, and biological efficiency. The fruiting bodies of $P$. djamor grown on this substrate contained $90.15 \pm 0.27 \%$ moisture, $0.87 \pm 0.22 \%$ ash, $0.12 \pm 0.00 \%$ crude protein, $0.17 \pm .01 \%$ crude fat, $3.10 \pm 0.24 \%$ crude fiber, and $5.59 \%$. nitrogen free extract.

\section{REFERENCES}

Arisha Mohamed Hamed Mohamed El-Hady. 2010. "Optimum Medium for Oyster Mushroom Production.”(Unpublished Master's Thesis) Zagazig University. Accessed December 29, 2016. www.academia.edu/9849562/OPTIMUM_MEDIUM_FOR_OYSTER_MUSHROOM_PRODUCTI $\mathrm{ON}$

Awi-Waadu Grace. D. and Herbert O. Stanley. 2010. "Effect of Substrates of Spawn Production on Mycelial Growth of Oyster Mushroom Species." Research Journal of Applied Sciences 5 (3): 161-164.

Chang, Shu-ting and Phillip .G. Miles. 2004. Cultivation, Nutritional Value, Medicinal Effect, and Environmental Impact of Mushrooms. $2^{\text {nd }}$ Ed. USA: CRC Press.

Chang Shu-ting and William Alfred Hayes. 1978. The Biology and Cultivation of Edible Mushrooms. USA: Elsevier. 842 p. 
Chang Hyun Yu, Sung Wu, Jeon, Alma Cosadio, Casimero.L. Icalina, Rodel Panganiban, Rosalita Quirino and Yanghoon Song. 2014. "Status and Prospect of Mushroom Industry in the Philippines." JPAIR Multidisciplinary Research 16: 151-153

Custodio D. John Christopher . 2004. Oyster Mushrooms Substrates. Mushroom Growers Handbook. Mushworld. www.mushworld.com/home

Ding, Teck Y.,Siew. L. Hii, and Lisa. G. Ong. 2012. "Comparison of Pretreatment Strategies for Conversion of Coconut Husk Fiber to Fermentable Sugars.” Bioresources 7(2): 1540-1547.

Gupta, Yash and Joshi B. Vijay. 1991. "Post-Composting Supplementation in Agaricus bisporus under Seasonal Growing Conditions." Paper presented at the 13th International Congress of International Conference on Mushroom Biology and Biotechnology, Dublin, Ireland, September 1-6.

Israel, Aniete. U., Regina E. Ogali, O. Onyewuchi Akaranta, and Idara.B. Obot. 2011. "Extraction and Characterization of Coconut (Cocosnucifera L.) Coir Dust." Songklanakarin Journal of Science and Technology 33(6): 717-724.

James Kennard S. Jacob, Sofronio P. Kalaw, and Renato G. Reyes. 2015. "Mycelial Growth Performance of Three Species of Pleurotus on Coconut Water Gelatin." Current Research in Environmental \& Applied Mycology 5(3), 263-268.

Khan, Nasir. Ahmad., Ajmal Jane Nicklin, Sadia. Aslam, and Asif M. Ali. 2013. "Nutritional Value of Pleurotus djamor Cultivated on Sawdusts of Different Woods." Pakistan. Journal Botany. 45(3): 11051108.

Magday, JC R., Melfei E. Bungihan, and Rich Milton R. Dulay. 2014. "Optimization of Mycelial growth and Cultivation of Fruiting Body of Philippine Wild Strain of Ganoderma lucidum." Current Research in Environmental \& Applied Mycology 4 (2): 162-172.

Miles, Phillip. G. and Shu-Ting Chang. 1997. Mushroom Biology: Concise Basics and Current Development. USA: World Scientific Publishing.

Mohapatra, Debabandya., Sabyasachi Mishra, and, Namrata Sutar. 2010. "Banana and Its By-product Utilization: An Overview." Journal of Scientific and Industrial Reasearch 69: 323-329.

Moyin-Jesu, Emmanuel. Ibukonoluwa., C.S. Iyoha, and M.O Akinola. 2012. "Comparative Evaluation of Different Organic Media on Soil Chemical Composition, Growth, and Yield of Mushroom (Pleurotus tubergium L.)." ISRN Agronomy 2012: Article ID 152737. doi: $\underline{10.5402 / 2012 / 152737}$

Nahr, Deborah. Louisa., Mary Obodai, Bakare Adijat Arowolo and Matilda Dzomeku, 2011. “The Efficacy of Sorghum and Millet Grains in Spawn Production and Carpophore Formation of Pleurotus ostreatus (Jacq. Ex. Fr).” Kummer. International Food Research Journal 18(3): 1143-1148 M.

Prades, Alexia, Manuel Dornier, Naffisatou Diop and Jean-Peirre Pain. 2012. "Coconut Water Uses, Composition, and Properties: A Review. Fruits 67 (2): 87-107. 
Paul E. Stamets. 2000. Growing Gourmet and Medicinal Mushrooms. New York, NY: Ten Speed Press.

Radenahmad Nisaudah, Farid Saleh, Kitja Sawangjaroen, Wilart Rundorn, Boornsirm Withyachumnarnkul and James R. Connor. 2009. "Young Coconut Juice Significantly Reduces Histopathological Changes in the Brain that are Induced by Hormonal Imbalance: A Possible Implication to Postmenopausal Women.” Histology \& Histopathology 24(6): 667-74.

Rau Udo. 1999. "Production of Schizophyllan." In Methods in Biotechnology, Carbohydrate Biotechnology Protocols, edited by Christopher Bucke, 43-55. New Jersey: Humanapress.

Santoso Umar, Kasuhiro Kubob, Toru Otac, Tadahiro Tadokoro, and AkioMaekawa. 1999. "Nutrient Composition of Kopyor Coconuts (Cocos nucifera L.).” Food Chemistry Journal. 57(2): 299-304.

Sjostrom, Eero. 1993. Wood Chemistry: Fundamentals and Applications. $2^{\text {nd }}$ ed. San Diego: Elsevier Inc.r.

Tinoco, Raunel., Michael A. Pickard, and Rafael Vasquez-Duhalt. 2001. "Kinetic Differences of Purified Lacasses From Six Pleurotus Ostreatus Strains." Letters in Applied Microbiology 32 (5): 331 335.

Victor, Wabali C. and Wocha Ifeanyi. 2013. "The Effect of Nutrient Concentration on the Yield of Mushroom (Pleurotus ostreatus)." Greener Journal of Agricultural Sciences 3(6): 437-444.

Yong, Jean W. H., Yan Fei Ng, Liya Geand Swee Ngin Tan. 2009. "The Chemical Composition and Biological Properties Of Coconut (Cocos Nucifera L.) Water. Molecules 14(12): 5144-5164.

Xiao, Bei Sun, Xue Feng and Runcang Sun. 2001. "Chemical, Structural, and Thermal Characterizations of Alkali - Soluble Lignin and Hemicelluloses, and Cellulose From Maize Stems, Rye Straw, and Rice Straw.” Polymer Degradation and Stability 74: 307-319. 